\title{
Predictability of Fetal Doppler, Biophysical Profile, and Cardiotocography for Fetal Acidosis at Birth
}

\author{
Ashutosh Gupta · Sanjay Mehta - Tauqeer Syed Fazal • \\ Renu Raina Sehgal • Ashima Gogia
}

Received: 28 September 2014/ Accepted: 8 December 2014/Published online: 18 December 2014

(C) Society of Fetal Medicine 2014

\begin{abstract}
Fetal Doppler has allowed evaluation of the fetus in both physiological and pathological conditions which has helped in establishing the relationship between Doppler and fetal oxygenation. It is difficult to define pathological acidosis, but the threshold $\mathrm{pH}$ of $<7$ is the best independent predictor for unexplained seizures. Most infants tolerate acidemia well and recover without any remarkable long term sequelae. Worsening umbilical artery acidosis is directly and adversely related to worsening of neurological outcome, hypoxic ischemic encephalopathy, and multiorgan involvement with permanent neurologic injury. Hypoxic ischemic encephalopathy events are not limited to high-risk pregnancies but may occur in about $50 \%$ of the low-risk population. Combination of low pH at birth with other abnormal clinical parameters, e.g., requirement for intubation, $5 \mathrm{~min}$ Apgar score $\leq 5$ has $80 \%$ positive predictability of seizures. Predictability of fetal Doppler examination for asphyxiated fetuses is in the tune of $86 \%$. High-risk pregnancies are screened antenatally by fetal Doppler, biophysical profile, and CTG to identify at-risk fetuses which are confirmed by the ABG analysis of cord blood immediately after birth. All these noninvasive modalities complement each other to identify,
\end{abstract}

\footnotetext{
A. Gupta $(\bowtie)$

Department of Fetal Medicine \& Clinical Genetics, Max Super Speciality Hospital, West Block, 1 Press Enclave Road, Saket, New Delhi 110017, India

e-mail: dr_ashutosh75@rediffmail.com

S. Mehta - T. S. Fazal

Department of Radiology, Artemis Health Institute, Gurgaon, Haryana, India

R. R. Sehgal · A. Gogia

Department of Obstetrics \& Gynecology, Artemis Health Institute, Gurgaon, Haryana, India
}

at the earliest, any clinical deterioration. Isolated abnormal, e.g., absent end diastolic flow in umbilical artery, abnormal biophysical profile, or nonreactive CTG are not adequately sensitive in identifying these fetuses which was observed in the present cohort. Thus, fetal Doppler in combination with biophysical profile supplemented with cardiotocograph helps in identifying at-risk fetuses for fetal acidosis and encephalopathy and helps in considering early intervention.

Keywords Fetal Doppler - Biophysical .

Cardiotocograph · Hypoxemia - Acidosis - Apgar score . Predictability $\cdot$ Seizures

\section{Introduction}

Fetal Doppler has allowed evaluation of the fetus in both physiological and pathological conditions which has helped in establishing the relationship between Doppler and fetal oxygenation. It is known that increased impedance to uteroplacental circulation is directly related to fetal hypoxemia. It stimulates preferential bloodflow to the brain, heart and adrenals; however, it does not necessarily correlate with hypercapnia and acidosis [1]. But, when this compensatory mechanism fails, it leads to increased pulsatility in the venous circulation which helps in optimizing the timing of delivery [2].

Acidosis is usually well tolerated by the fetus without any sequela. When fetal cord blood $\mathrm{pH}$ is $>7.0$ or base excess is less than minus 12 it does not necessarily have an adverse effect on the fetal cognition or long term complications [3]. It is difficult to define pathological acidosis, but Williams et al. have recommended the threshold $\mathrm{pH}$ of $<7$ as the best independent predictor for unexplained seizures [4]. 


\section{Materials and Methods}

Umbilical vein sampling was done immediately after the baby was born after doubly ligating the umbilical cord. Cord blood arterial blood gas analysis (ABG) was done to identify fetal acidosis after birth. $\mathrm{ABG}$ included $\mathrm{pH}, \mathrm{pCo}_{2}$, base excess and lactate. Fetal carbon di-oxide may be removed from the umbilical arterial blood and venous circulation has shown to have slightly higher $\mathrm{pH}$ and lower $\mathrm{pCo}_{2}$ than the arterial blood [5]. Restriction of blood flow in the umbilical cord adversely affects the blood gases, as in cases of tight nuchal cord [6], cord prolapsed [7], or placental abruption with cord obstruction [8]. Even though these techniques have their limitations, yet if used within their specific domain, these may be of immense help to identify at-risk fetuses and to take appropriate measures to prevent neurological impairment.

\section{Results}

High-risk antenatal cases were followed-up prospectively in the department of Fetal Medicine at Artemis hospital with fetal Doppler, biophysical profile, and antenatal or intrapartum cardiotocograph (CTG). ABG analysis was done after birth in all the cases. All these antenatal screening tools were utilized for predicting worsening of the clinical situation and to identify at an earliest, the fetuses at risk of fetal hypoxemia and acidosis (Fig. 1).

This cohort of eight high-risk cases with their clinical presentation is depicted in Table 1; the fetal Doppler assessment and $\mathrm{ABG}$ analysis after birth are shown in Tables 2 and 3, respectively.

Cohort of high risk was defined by the fetal abdominal circumference or fetal weight $<25$ th centile for the gestational age; abnormal Doppler when umbilical or uterine artery pulsatility index (PI) is $>95$ th centile for the gestational age; abnormal biophysical profile by any score of $4 / 8$ or less and nonreactive CTG (Figs. 2, 3).

Intrauterine growth restriction (IUGR) was identified in 4 cases (case no. 2, 6, 7, and 8). However, acidosis was identified in only 1 case (case no. 8), when the biophysical score dipped to $4 / 8$ with nonreactive CTG. Two cases (case no 6 and 8) had biophysical score of $4 / 8$ and nonreactive CTG (case no 4 and 8) but only 1 (case no. 4) had both of them abnormal and had severe respiratory acidosis. One case (case no. 6) with biophysical score of $4 / 8$ had a reactive CTG and the other one (case no. 4) with normal biophysical score had nonreactive CTG but both of them had normal $\mathrm{pH}$.

Absent end diastolic flow in the umbilical artery was identified in 2 preterm fetuses (case no. 2 and 3), but both of them had normal CTG and normal $\mathrm{pH}$ at birth. Fetal acidosis was identified more commonly in term pregnancies (case no. 4 and 8) as compared to preterm fetuses.

Identification of absent end diastolic flow led to the decision to expedite the delivery before ominous venous Doppler appeared to prevent irreversible fetal outcome. One case with nuchal cord with high resistance in the cord was identified to have fetal acidemia (case no. 4). Both the cases of fetal acidemia had high levels of lactate (cases no. 4 and 8, Table 2) depicting an intrinsic metabolic derangement.

\section{Discussion}

Predictability of fetal Doppler examination for asphyxiated fetuses is in the tune of $86 \%$ [9]. Even then, most infants tolerate acidemia well and recover without any remarkable long term sequelae [10]. Worsening umbilical artery acidosis is directly and adversely related to worsening of neurological outcome, hypoxic ischemic encephalopathy, multiorgan involvement with permanent neurologic injury.
Fig. 1 Increased resistance to blood flow in the umbilical artery in nuchal cord and normal blood flow in the free loop of umbilical cord in case no. 4 (Table 1)

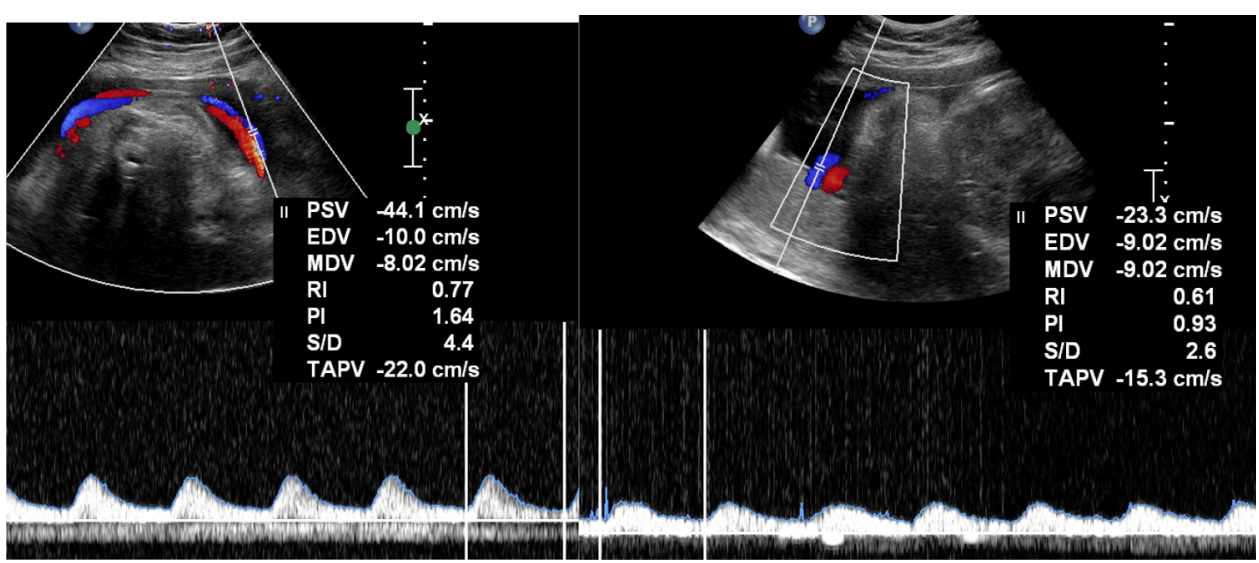




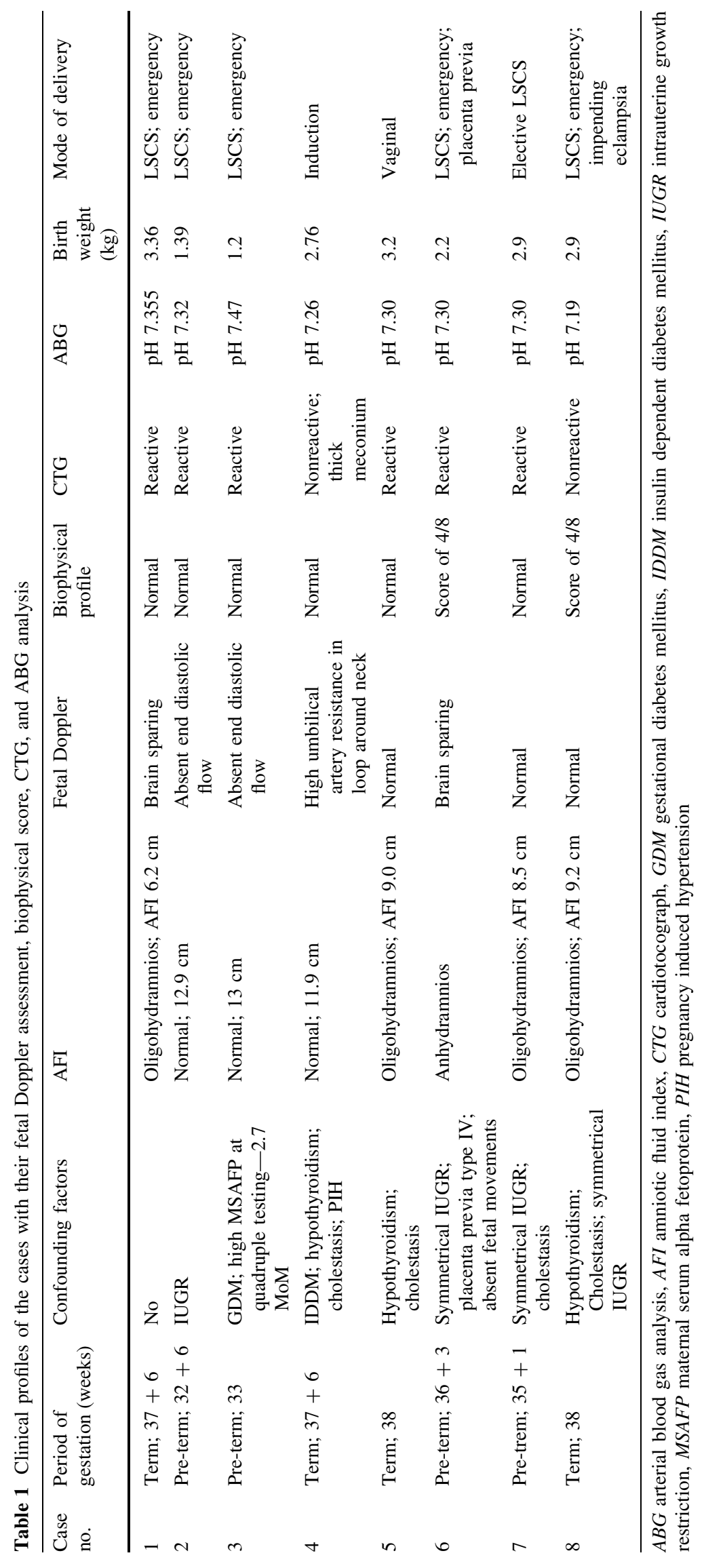




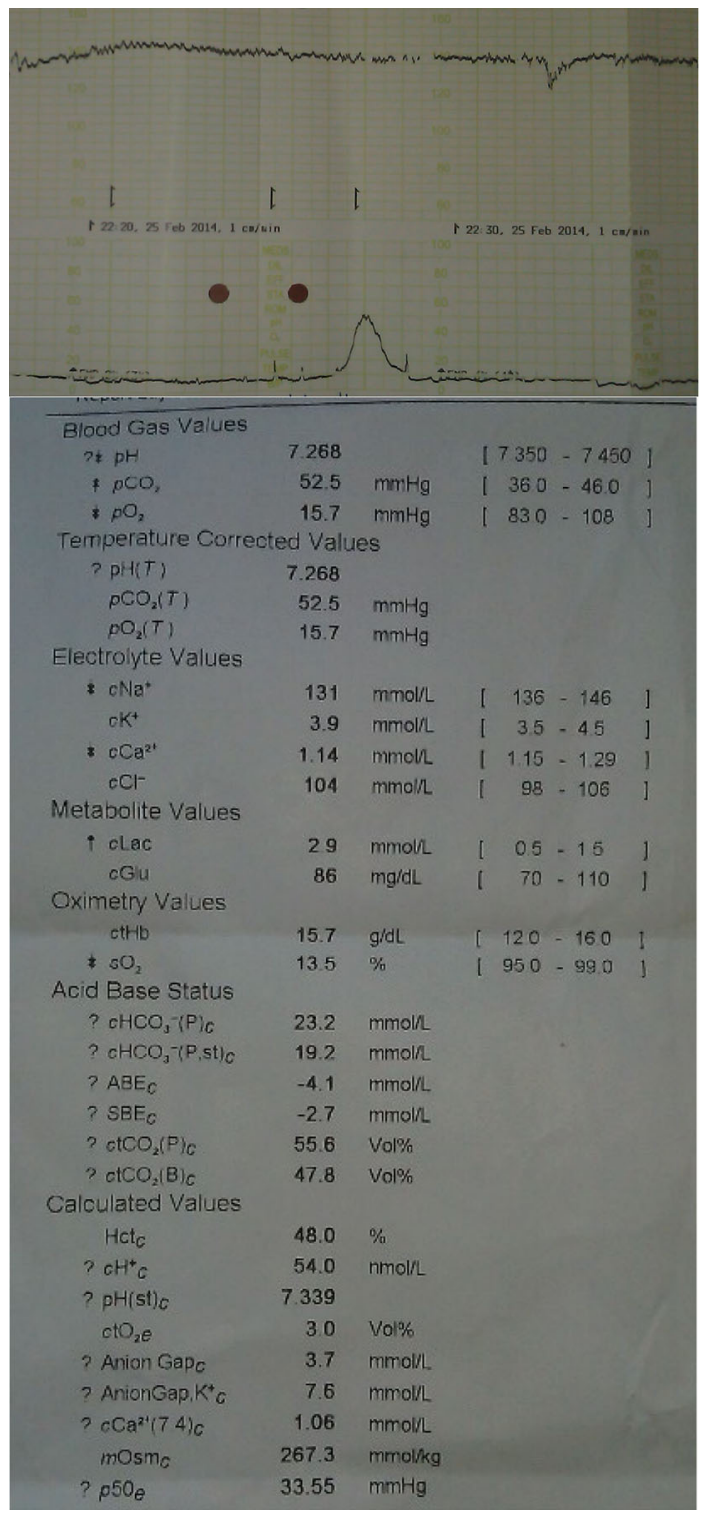

Fig. 2 Nonreactive cardiotocograph (CTG) with loss of baseline variability with arterial blood gas $(\mathrm{ABG})$ analysis of the fetus showing mixed acidosis in case no. 4 (Table 1)

Combination of low $\mathrm{pH}$ at birth with other abnormal clinical parameters, e.g., requirement for intubation, $5 \mathrm{~min}$ Apgar score $\leq 5$ has $80 \%$ positive predictability of seizures [11]. However, in the present series, both the acidotic fetuses responded very well to the treatment and recovered without any sequela.

Noninvasive antenatal techniques to predict mortality in preterm fetuses is almost similar to that of term fetuses. Inspite of absent end diastolic flow in umbilical artery in two preterm fetuses, none of them had acidosis stresses, the fact that surviving preterm fetuses tend to have higher umbilical artery $\mathrm{pH}$ as compared to those who die [12].

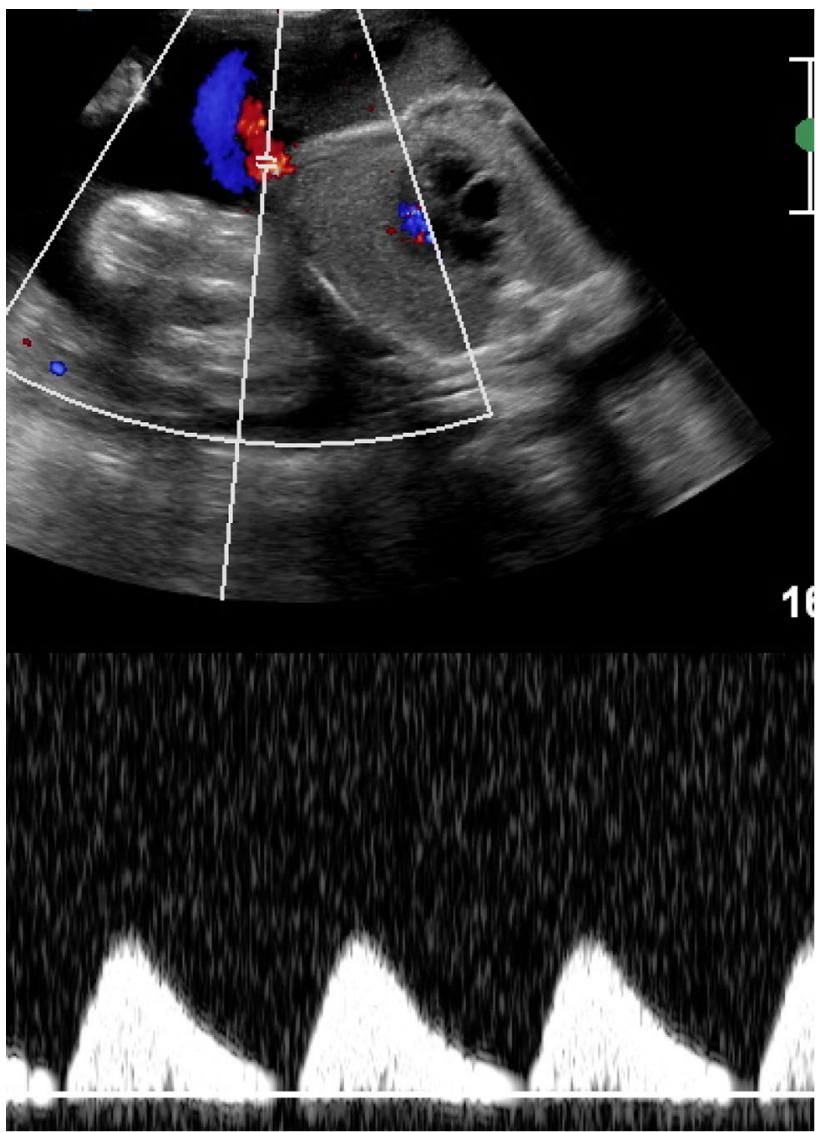

Fig. 3 Absent end diastolic flow in the umbilical artery in case no. 2 and 3 (Table 1)

Cord blood lactate has been identified to be almost fetal in origin and since it does not cross the placenta, it correlates very well with $\mathrm{pH}$ and base excess [13]. In the present series, both the cases of fetal acidemia had high lactate, which is a very specific sign of anaerobic metabolism and has high sensitivity (approaching $100 \%$ ) and specificity $(95.4 \%)$ for predicting neonatal encephalopathy [14].

In this series, none of the cases with absent end diastolic flow in umbilical artery had acidosis which is in concordance with the fact that markedly reduced or absent end diastolic flow of umbilical artery is an independent risk factor for fetal hypoxia and acidosis [15]. However, both the cases were delivered before the reversal of arterial flow or the venous changes appeared, as the fetuses with abnormal venous Doppler have worse prognosis [16] with almost all of them at risk of being asphyxiated [17].

Predictability of fetal biophysical score of $\leq 6$ [18] and abnormal CTG trace for fetal acidosis $(\mathrm{pH}<7.25)$ is only 50-65 \% [19]. However, in the present series, when both low biophysical score was associated with loss of variability on CTG, the fetus was found to be acidotic. Growth 


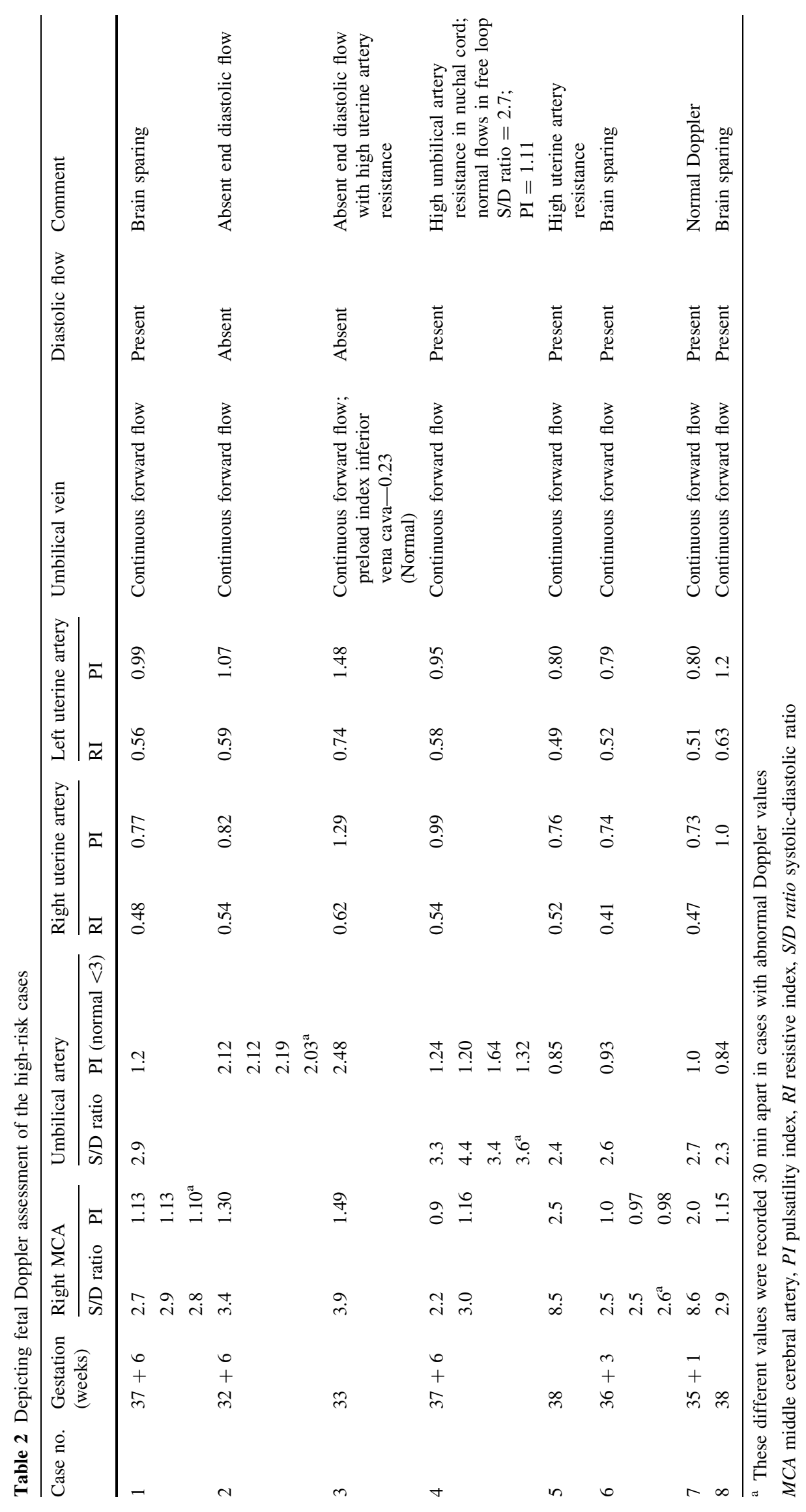


Table 3 Depicting arterial blood gas analysis of the cases

\begin{tabular}{|c|c|c|c|c|c|c|}
\hline $\begin{array}{l}\text { Case } \\
\text { no. }\end{array}$ & $\mathrm{pH}$ & $\mathrm{pCO}_{2}$ & Lactate & $\mathrm{HCO}_{3}$ & $\begin{array}{l}\text { Base } \\
\text { excess }\end{array}$ & Interpretation \\
\hline 1 & 7.3 & 44.0 & 1.5 & 23.9 & -1.4 & $\begin{array}{l}\text { Mild mixed } \\
\text { acidosis }\end{array}$ \\
\hline 2 & 7.3 & 45.0 & 2.0 & 22.6 & -3.2 & $\begin{array}{l}\text { Mild mixed } \\
\text { acidosis }\end{array}$ \\
\hline 3 & 7.4 & 40.0 & 3.5 & 23.5 & 0.4 & Normal pH \\
\hline 4 & 7.2 & 52.5 & 2.9 & 23.2 & -4.1 & Mixed acidosis \\
\hline 5 & 7.36 & 45.0 & 1.3 & 25.3 & 0.2 & Normal pH \\
\hline 6 & 7.3 & 42.2 & 2.0 & 18.0 & -1.1 & Metabolic acidosis \\
\hline 7 & 7.5 & 41.5 & 1.5 & 32.0 & -2.4 & $\begin{array}{l}\text { Metabolic } \\
\text { alkalosis }\end{array}$ \\
\hline 8 & 7.1 & 63.7 & 3.7 & 23.8 & -6.1 & $\begin{array}{l}\text { Severe respiratory } \\
\text { acidosis }\end{array}$ \\
\hline
\end{tabular}

restricted fetuses with brain sparing may have hypoxemia and, if complicated with abnormal fetal Doppler and ominous CTG, may have associated fetal acidosis.

\section{Conclusion}

As early as 1958, umbilical cord blood gas analysis was being utilized to identify fetal hypoxic stress [20]. Ever since, it has been widely accepted and now recommended by both American and British College of Obstetricians and Gynecologists to all the high-risk deliveries with its increasing clinical and medico-legal importance [21, 22]. Hypoxic ischemic encephalopathy events are not limited to high-risk pregnancies. They may occur in about $50 \%$ of the low-risk population [23], and thus is recommended in all high-risk deliveries.

High-risk pregnancies are screened antenatally by fetal Doppler, biophysical profile, and CTG to identify at-risk fetuses which is confirmed by ABG analysis of cord blood immediately after birth. All these noninvasive modalities complement each other to identify at the earliest any clinical deterioration. Isolated abnormal, e.g., absent end diastolic flow in umbilical artery, abnormal biophysical profile, or nonreactive CTG are not adequately sensitive in identifying these fetuses which is observed in the present cohort.

Fetal Doppler in combination with biophysical profile supplemented with CTG helps in identifying at-risk fetuses for fetal acidosis. Umbilical cord blood gas analysis in combination with other clinical parameters, Apgar scores, need for ventilation, cardiopulmonary compromise, helps in identifying at-risk infants for encephalopathy and to consider early intervention.

\section{Conflict of interest None.}

\section{References}

1. Bilardo CM, Nicolaides KH, Campbell S. Doppler measurements of foetal and uteroplacental circulations: relationship with umbilical venous blood gases measured at cordocentesis. Am J Obstet Gynecol. 1990;162(1):115-20.

2. Hecher K, Snijders R, Campbell S, Nicolaides K. Foetal venous, intracardiac, and arterial blood flow measurements in intrauterine growth retardation: relationship with foetal blood gases. Am J Obstet Gynecol. 1995;173(1):10-5.

3. Svirko E, Mellanby J, Impey L. The association between cord pH at birth and intellectual function in childhood. Early Hum Dev. 2008;84(1):37-41.

4. Williams KP, Singh A. The correlation of seizures in newborn infants with significant acidosis at birth with umbilical artery cord gas values. Obstet Gynecol. 2002;100(3):557-60.

5. Westgate J, Garibaldi JM, Greene KR. Umbilical cord blood gas analysis at delivery: a time for quality data. Br J Obstet Gynaecol. 1994;101(12):1054-63.

6. Martin GC, Green RS, Holzman IR. Acidosis in newborns with nuchal cords and normal Apgar scores. J Perinatol. 2005; 25(3):162-5.

7. Johnson JW, Richards DS. The etiology of foetal acidosis as determined by umbilical cord acid-base studies. Am J Obstet Gynecol. 1997;177(2):274-80.

8. Pomerance J. Umbilical cord blood gas casebook. Interpreting umbilical cord blood gases, IX. J Perinatol. 2001;21(7):469.

9. Stark JE, Seibert JJ. Cerebral artery Doppler ultrasonography for prediction of outcome after perinatal asphyxia. J Ultrasound Med. 1994;13(8):595-600.

10. King TA, Jackson GL, Josey AS, et al. The effect of profound umbilical artery acidemia in term neonates admitted to a newborn nursery. J Pediatr. 1998;132(4):624-9.

11. Perlman JM, Risser R. Can asphyxiated infants at risk for neonatal seizures be rapidly identified by current high-risk markers? Pediatrics. 1996;97(4):456-62.

12. Hibbard JU, Hibbard MC, Whalen MP. Umbilical cord blood gases and mortality and morbidity in the very low birth weight infant. Obstet Gynecol. 1991;78(5 Pt 1):768-73.

13. Krüger K, Kublickas M, Westgren M. Lactate in scalp and cord blood from foetuses with ominous foetal heart rate patterns. Obstet Gynecol. 1998;92(6):918-22.

14. Chou YH, Tsou Yau KI, Wang PJ. Clinical application of the measurement of cord plasma lactate and pyruvate in the assessment of high-risk neonates. Acta Paediatr. 1998;87(7):764-8.

15. Tyrrell S, Obaid AH, Lilford RJ. Umbilical artery Doppler velocimetry as a predictor of foetal hypoxia and acidosis at birth. Obstet Gynecol. 1989;74:332.

16. Baschat AA, Gembruch U, Reiss I, et al. Relationship between arterial and venous Doppler and perinatal outcome in foetal growth restriction. Ultrasound Obstet Gynecol. 2000;16(5): 407-13.

17. Brar HS, Platt LD. Reverse end-diastolic flow velocity on umbilical artery velocimetry in high-risk pregnancies: an ominous finding with adverse pregnancy outcome. Am J Obstet Gynecol. 1988;159(3):559-61.

18. Yoon BH, Romero R, Roh CR, et al. Relationship between the foetal biophysical profile score, umbilical artery Doppler velocimetry, and foetal blood acid-base status determined by cordocentesis. Am J Obstet Gynecol. 1993;169(6):1586-94.

19. Parer JT. Efficacy and safety of intrapartum electronic foetal monitoring: an update. Obstet Gynecol. 1996;87(3):476-7.

20. James LS, Weisbrot IM, Prince CE, et al. The acid-base status of human infants in relation to birth asphyxia and the onset of respiration. J Pediatr. 1958;52(4):379-94. 
21. Goddard R. Electronic foetal monitoring is not necessary for low risk labours. BMJ. 2001;322(7300):1436-7.

22. ACOG Committee on Obstetric Practice. ACOG Committee Opinion No. 348, November 2006: umbilical cord blood gas and acid-base analysis. Obstet Gynecol. 2006;108(5):1319-22.
23. Sameshima H, Ikenoue T, Ikeda T, et al. Unselected low-risk pregnancies and the effect of continuous intrapartum foetal heart rate monitoring on umbilical blood gases and cerebral palsy. Am J Obstet Gynecol. 2004;190(1):118-23. 